\title{
First spike latency sensitivity of spiking neuron models
}

\author{
Laura Trotta ${ }^{1 *}$, Alessio Franci ${ }^{2}$, Rodolphe Sepulchre ${ }^{1,2}$ \\ From Twenty Second Annual Computational Neuroscience Meeting: CNS*2013 \\ Paris, France. 13-18 July 2013
}

First spike latency is the long-lasting period preceding the first spike of a neuron submitted to a super-threshold stimulus. It has been suggested that this latency could code for stimulus recognition in several sensory systems $[1,2]$.

To encode information reliably, first spike latency should be sensitive to sensory inputs but robust to external perturbations. This paper studies the robustness of the first spike latency in spiking neuron models. These models are nonlinear and possibly highdimensional. Understanding which parameters govern the first spike latency sensitivity in these systems generally requires extensive numerical simulations. We show that a local sensitivity analysis of the system is a good predictor of the global robustness of the latency code. This analysis, motivated by previous work on delayed decision-making in bistable models [3], relies on the assumption that the model posses a saddle node bifurcation with a sufficiently attractive center manifold. Results are illustrated on a 6-dimensional model including a $\mathrm{K}^{+}$-current of type A [4], a current of particular importance for first spike latencies, see Figure 1.

Our results show that first spike latency coding is particularly robust for a new type of excitability called regenerative excitability [5].

\section{A}

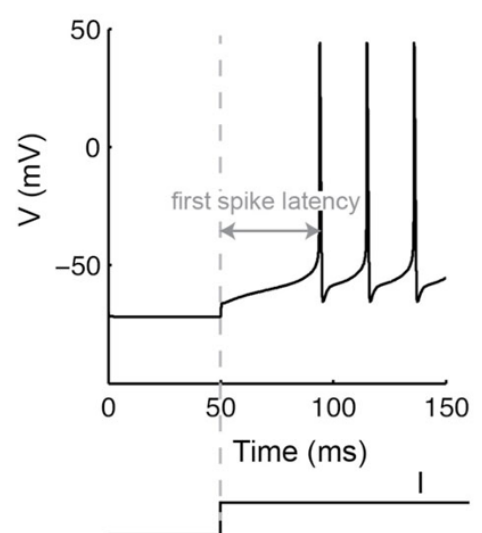

B

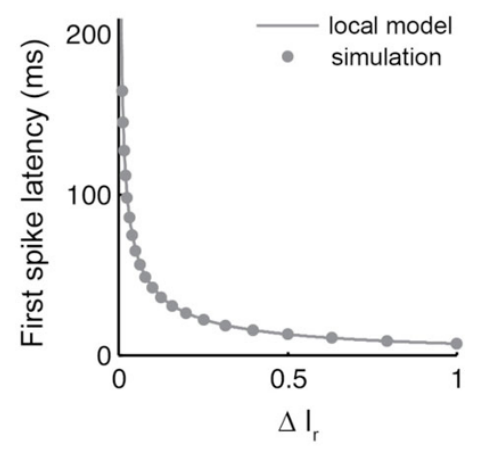

Figure 1 First spike latency in [4]when the Type A-current conductance is set to a value which corresponds to regenerative excitability. When the current is slightly above the saddle node, the neuron presents a robust first spike latency (A). First spike latency decreases with the relative variation of current $\Delta \mid r$, i.e the distance to the saddle node bifurcation (B). Analytical predictions of a local model (solid line) fit the results obtained by numerical simulations of the full model (dots).

\footnotetext{
* Correspondence: I.trotta@ulg.ac.be

'Department of Electrical Engineering and Computer Science, University of Liège, Liège, 4000, Belgium

Full list of author information is available at the end of the article
} 


\section{Author details}

${ }^{1}$ Department of Electrical Engineering and Computer Science, University of Liège, Liège, 4000, Belgium. ${ }^{2}$ Centre de recherché Inria Lille-Nord Europe,

Parc scientifique de la Haute Borne, Villeneuve d'Ascq, 59650, France.

Published: 8 July 2013

\section{References}

1. Gollisch T, Meister M: Rapid neural coding in the retina with relative spike latencies. Science 2008, 319(5866):1108-1111.

2. Johansson RS, Birznieks I: First spikes in ensembles of human tactile afferents code complex spatial fingertip events. Nat Neurosci 2004, 7(2):170-177.

3. Trotta L, Bullinger E, Sepulchre R: Global analysis of dynamical decisionmaking models through local computation around the hidden saddle. PLoS One 2012, 7(3):e33110.

4. Connor JA, Stevens CF: Prediction of repetitive firing behaviour from voltage clamp data on an isolated neurone soma. J Physiol 1971, 213(1):31-53.

5. Drion G, Franci A, Seutin V, Sepulchre R: A novel phase portrait for neuronal excitability. PLoS One 2012, 7(8):e41806.

doi:10.1186/1471-2202-14-S1-P354

Cite this article as: Trotta et al:: First spike latency sensitivity of spiking neuron models. BMC Neuroscience 2013 14(Suppl 1):P354.

\section{Submit your next manuscript to BioMed Central} and take full advantage of:

- Convenient online submission

- Thorough peer review

- No space constraints or color figure charges

- Immediate publication on acceptance

- Inclusion in PubMed, CAS, Scopus and Google Scholar

- Research which is freely available for redistribution

Submit your manuscript at www.biomedcentral.com/submit 